\title{
Los actores y la privatización del servicio de limpia en Ciudad Juárez, Chihuahua
}

\author{
Gustavo Córdova Bojórquez, Lourdes Romo Aguilar, \\ Cecilia Sarabia Ríos e Israel Díaz Arcos*
}

\begin{abstract}
Resumen. El presente trabajo ofrece un análisis de las posibilidades de que se implemente con éxito un sistema de concesión del servicio de recolección y confinamiento de los residuos sólidos urbanos no peligrosos en Ciudad Juárez. La identificación de las posturas de los diferentes actores que generan la ciudad a través de una revisión hemerográfica, una encuesta aleatoria a hogares y entrevistas a líderes de opinión nos permitió establecer que existe una alta politización en el manejo de la basura en la ciudad que obstaculiza implementar alternativas que exigen invariablemente eficiencia, eficacia, transparencia y participación ciudadana.

Palabras clave: actores, privatización, basura, política, gobernabilidad.
\end{abstract}

\begin{abstract}
This document offers an analysis about possibilities to implement a concession system in the recollection and disposal of non-hazardous trash collection service in Ciudad Juarez. The recognition of view points from different actors in the timeframe, applying a survey to home heads and interviews to opinion leaders, as actors key in city's production, let us to identify a high politized item that keep off efficient and transparent public participation. Keywords: actors, privatization, solid waste, politics, gobernance.
\end{abstract}

* El Colegio de la Frontera Norte, Dirección General Regional de Ciudad Juárez. Correos electrónicos, por orden de enunciación: gcordova@colef.mx, lromo@colef.mx, csarabia@colef.mx, idiaz@colef.mx 


\section{Introducción}

Dentro de los servicios de consumo colectivo, el de limpia (recolección y confinamiento de basura generada en casas habitación) representa un reto para las autoridades, sobre todo si consideramos que un mal manejo de este servicio afecta directamente la salud y la calidad de vida de los habitantes y ofrece una mala imagen urbana con sus respectivas repercusiones en el desarrollo de la ciudad.

En su afán de mantener un buen servicio, el gobierno de Ciudad Juárez ha sostenido con recursos propios el sistema de limpia, el cual incluye infraestructura, equipo sofisticado y el aparato burocrático. Dicho sistema representa para el Ayuntamiento un costo que repercute en las finanzas públicas, toda vez que hay que sufragar un gasto corriente superior a los 143 millones de pesos (mdp) anuales, que según la Dirección General de Servicios Públicos Municipales ${ }^{1}$ se encuentran distribuidos de la siguiente manera: $83.2 \mathrm{mdp}$ en el servicio de recolección y relleno sanitario; 26.18 mdp en administración (nóminas principalmente); 12 mdp en servicios médicos; $1.3 \mathrm{mdp}$ en pago de jornales; $0.78 \mathrm{mdp}$ en pago de electricidad; $0.2 \mathrm{mdp}$ en el Programa de Destilichadero; y el resto, que corresponde a $19.24 \mathrm{mdp}$, en contingencias y demás actividades de la dirección.

El gasto de inversión se ha incrementado con los años. Es preciso mencionar que se necesita sustituir al menos 70 de las 112 unidades de recolección de basura para mejorar el servicio. Ante esta disyuntiva, tanto el Ayuntamiento como los actores sociales interesados deben preguntarse si es pertinente que el primero siga sosteniendo económicamente un servicio de consumo colectivo, habiendo alternativas como la iniciativa privada, y entonces, destinar parte de estos recursos a realizar otras tareas de gobierno.

Dada esta situación, es preciso analizar los aspectos que engloba el servicio de limpia, como los técnicos, económicos y sociales. Este trabajo expone los aspectos sociales con el siguiente objetivo: analizar las posiciones de los diferentes actores que producen la ciudad res-

${ }^{1}$ Entrevista al ingeniero Ricardo Abud, director técnico de la Dirección General de Servicios Públicos, 16 de mayo de 2006. 
pecto al servicio de limpia y las posibilidades de que se implemente con éxito un sistema de concesión del servicio de recolección y confinamiento de los residuos sólidos urbanos no peligrosos.

Para cumplir con este objetivo, el trabajo se ha dividido en cinco partes. La primera muestra el marco conceptual y metodológico; la segunda analiza a los actores en el tiempo a partir de una revisión hemerográfica; la tercera estudia la posición de los jefes de hogar de la ciudad; la cuarta parte concentra la opinión de líderes de opinión, y en la quinta y última se exponen las conclusiones.

\section{Marco conceptual y metodológico}

\section{Marco conceptual}

La ciudad puede ser entendida como un orden físico social que distribuye, por una parte, a los grupos sociales, las familias y los individuos, y, por otra, a los satisfactores, tales como la infraestructura, los equipamientos y los servicios. Los servicios son uno de los componentes fundamentales de la funcionalidad urbana y, en particular, de su papel en la distribución social de bienes. Constituyen una mediación entre las dimensiones territoriales y sociales de la distribución (Pirez, 1999). Los servicios como agua, energía eléctrica, gas, teléfono, recolección de basura, etc., permiten a los usuarios participar de los componentes fundamentales de la vida urbana. La falta de esos servicios implica, en consecuencia, una carencia grave para quienes están territorialmente incorporados a la ciudad.

Dichos servicios, sin embargo, comparten una serie de características que es necesario sistematizar: $a$ ) tienen el carácter de necesidad general; $b$ ) requieren inversiones de gran escala; $c$ ) su expansión responde al crecimiento económico y al proceso de urbanización; ${ }^{2}$ y

${ }^{2}$ El modelo de ocupación del suelo en Ciudad Juárez se ha caracterizado por una urbanización acelerada, con bajas densidades y la ocupación de grandes extensiones de terreno. Algunas de las principales causas de dicho modelo son la especulación del suelo, la existencia de una amplia diferencia de ingresos entre los diferentes grupos sociales, la participación de agentes formales e informales dentro de la producción del espacio urbano, los distintos regímenes de propiedad, 
d) son de baja rentabilidad y con una lenta rotación de capital (Garza, 1985).

A estas características debemos sumar que los servicios urbanos son una realidad compleja que puede ser percibida como un sistema de relaciones entre diferentes actores, el cual es regulado por un conjunto de normas y es objeto de procesos de gestión. Esa gestión es una articulación de recursos humanos, naturales y financieros para producir un bien determinado. ${ }^{3}$

En forma sintética puede decirse que los servicios son un "sistema social", esto es, un sistema de relaciones entre sectores sociales que es objeto de cierta gestión (Pirez, 1999). De manera general se identifican en este sistema los siguientes tres actores: elaboradores de la política y planeación del servicio, productores del bien particular y usuarios.

En el caso del servicio de limpia de Ciudad Juárez, estos tres actores son: a) el gobierno municipal y el Ayuntamiento como elaboradores de la política y planeación; $b$ ) servicios públicos municipales y sindicato municipal, como productores del bien, y $c$ ) los ciudadanos como usuarios.

Se observa, en el caso que nos ocupa, la participación del Estado siguiendo el modelo tradicional de oferta de servicios de consumo colectivo como el agua y la electricidad. Según Ordoñez y Alegría (1991), la participación del Estado en este sector ha permitido históricamente la conservación de la tasa de ganancia del capital industrial. Por un lado, ha evitado presiones extraordinarias para incrementar los salarios subsidiando la producción de algunos servicios; por otra parte, ha transferido directamente a la industria los beneficios deriva-

la errática y cada vez menor participación del estado en las políticas urbanas y sociales, y la poca o nula regulación de las autoridades. Ello se ha traducido en la acelerada expansión de la mancha urbana, en una creciente especulación del suelo y en el aumento de la segregación espacial; además, ha originado que la cantidad de predios baldíos aumente (Díaz Arcos, 2004).

${ }^{3}$ La gestión pública, por su parte, se ocupa de la utilización de los medios adecuados para alcanzar un fin colectivo. Trata de los mecanismos de decisión para la asignación y distribución de los recursos públicos, y de la coordinación y estímulo de los agentes públicos para lograr objetivos colectivos. De esta manera, la decisión pública es un compromiso entre múltiples actores interdependientes (Meny y Thoenig, 1992). 
dos del proceso de urbanización, haciendo más eficientes los procesos de circulación; asimismo, la industria se ha beneficiado directamente de precios subsidiados de algunos insumos como la energía o el agua.

Por otro lado, la función política de los servicios públicos también ha cumplido una tarea básica para la conservación del esquema de dominación. El sistema político, además de legitimar su existencia mediante la producción masiva de satisfactores necesarios para la sociedad, utiliza esos espacios de gobierno como sobrevivencia y movilidad de la clase política.

Por su parte, la privatización de los servicios públicos ${ }^{4}$ nace con el redimensionamiento del Estado propuesto como uno de los ejes principales de las políticas neoliberales. Este proceso de transferencia al capital privado de la propiedad, el control y la gestión de soportes materiales, medios de producción y procesos de producción, intercambio y distribución social, incluye las "condiciones generales para la reproducción de la formación social", controladas hasta ahora por el sector público, entre otras: drenaje, recolección de desechos sólidos y líquidos, cementerios, educación, salud, etcétera (Padilla, 1991).

Actualmente, y dado el avance de las políticas neoliberales, se ejercen sobre el Estado cuatro tipos de presiones que le hacen perder el papel central en la política y el desarrollo: a) socialización del Estado, cuando la sociedad irrumpe desde adentro el monopolio burocrático partidista a través de diferentes comités de usuarios; $b$ ) estatización de la sociedad, es decir, el traspaso de la propiedad estatal a grupos privados; c) la democracia directa, referida a las prácticas de participación que no implica la intervención permanente dentro de las instituciones ni la delegación permanente de funciones de la sociedad, como por ejemplo los referendos, los plebiscitos y las consultas populares; y d) el control social del Estado, referido a todas las prácticas a las cuales acuden los ciudadanos, comunidades y grupos sociales para limitar el poder estatal (Restrepo, 2001).

\footnotetext{
${ }^{4}$ Se usa coloquialmente el término privatización, sin embargo, para el caso que nos ocupa el servicio de limpia no puede privatizarse puesto que el artículo 115 constitucional establece que los municipios tendrán a su cargo dicho servicio. La figura que se usa para que la iniciativa privada se haga cargo de un servicio público exclusivo del Estado es la de concesión por tiempo determinado.
} 
En la cumbre para la gobernabilidad progresista celebrada en Inglaterra el 13 y 14 de julio de 2003, convocada por el primer ministro de Inglaterra Tony Blair y en la cual participaron 14 países, la preocupación estribó en la definición de una "nueva agenda" progresista con base en tres principios rectores: la protección de la gente contra los riesgos de los cuales ésta no se puede proteger; el empoderamiento de las mujeres y de los hombres para controlar sus propias vidas, y la preparación de nuestras sociedades y economías para los retos del futuro.

En esta cumbre se define la nueva forma de trabajar de la socialdemocracia moderna o la nueva izquierda, que contiene una agenda global y una doméstica. De esta última se desprenden ocho temas fundamentales de los que resaltamos dos puntos: el primero de ellos hace referencia a que los servicios públicos deben ser un imperativo de los gobiernos garantizando el acceso justo a los servicios, mejorando la calidad y expandiendo las opciones y la diversidad para atender las necesidades de todos los componentes de la población. No están ni por la privatización como un fin en sí mismo, ni por concentrar en exclusividad la prestación de los servicios públicos. $\mathrm{Su}$ postulado en este campo es poner primero al ciudadano. El segundo punto se relaciona con la gobernabilidad y la democracia, y establece que para continuar profundizando la democracia, se requiere una gran transparencia, ética de servicio público, revincular a los políticos con la gente y comprometer más estrechamente a la población con la toma de decisiones.

Estos esquemas plantean sin duda un nuevo entendimiento entre gobierno y sociedad en el que no importan las ideologías, sólo cuenta el mejoramiento de las condiciones de reproducción social. De estas tendencias se recogen diversos instrumentos de gestión, como juntas, sindicatos, patronatos, comisiones, dependencias públicas desconcentradas, descentralizadas, mixtas, concesiones y servicios totalmente privados (Villers, 2004). Algunas de las modalidades en las que participa la iniciativa privada en la propiedad pública son: contratos de prestación de servicio y contratos de administración, arrendamiento, сот (construir, operar y transferir) y concesión integral (cuadro 1). 


\section{Cuadro 1.}

Tipo de asociaciones público-privadas

\begin{tabular}{|c|c|c|c|c|c|}
\hline & $\begin{array}{l}\text { Contratos } \\
\text { de } \\
\text { prestación } \\
\text { servicios }\end{array}$ & $\begin{array}{c}\text { Contratos } \\
\text { de } \\
\text { administración }\end{array}$ & Arrendamiento & O COT & $\begin{array}{l}\text { Concesión } \\
\text { integral }\end{array}$ \\
\hline Propiedad & Público & Público & Público & Público & Público \\
\hline Inversión & Público & Público & Público & Privado & Privado \\
\hline $\begin{array}{l}\text { Operación/ } \\
\text { mantenimiento }\end{array}$ & Público & $\begin{array}{l}\text { Privado } \\
\text { con riesgo } \\
\text { limitado }\end{array}$ & $\begin{array}{c}\text { Privado } \\
\text { con riesgo } \\
\text { total }\end{array}$ & Privado & Privado \\
\hline Cobro de tarifas & $\begin{array}{l}\text { Público/ } \\
\text { privado }\end{array}$ & $\begin{array}{l}\text { Público/ } \\
\text { privado }\end{array}$ & Privado & Público & Privado \\
\hline Duración (años) & $1-2$ & $3-15$ & $8-15$ & $20-30$ & $20-30$ \\
\hline
\end{tabular}

Fuente: Brook-Cowen (1997), Haarmeyer y Mody (1998) citado por Saade, 2005.

El tema de la privatización de los servicios genera diferentes puntos de vista que se centran, según Ordoñez y Alegría (1991), en que: 1. la racionalidad pública elimina de sus objetivos el margen de ganancia, condición indispensable para la función privada de producción; 2. cualquier incremento en los precios repercute con mayor intensidad en la base de la pirámide de ingresos; debido a la poca elasticidad-precio de los servicios públicos, ese incremento reduciría inevitablemente los niveles de bienestar social de grandes conglomerados poblacionales; y 3 . la racionalidad privada induciría a la empresa a modificar el contenido de sus políticas.

La búsqueda de la rentabilidad del capital, además de modificar las condiciones de producción, fijación de precios y distribución del servicio en el corto, mediano y largo plazos, transformaría los objetivos de la expansión de la cobertura de tal forma que la nueva inversión sería justificable sólo si las expectativas de crecimiento del mercado lo requieren. La eficiencia privada, en este marco, tendría efectos perniciosos sobre el beneficio social. Los parámetros para medir la eficiencia bajo las dos modalidades de administración, definen en última instancia los ejes rectores de su actividad. Entre 
privilegiar al beneficio privado o la cobertura social, quedarían resumidos gran parte de los argumentos de la polémica sobre la privatización de los servicios.

Aunado a esto, el Fondo Monetario Internacional (FMI) y el Banco Mundial (Bм) consideran que uno de los factores determinantes de la crisis económica ha sido el alto déficit presupuestal generado por el excesivo crecimiento del gasto social del Estado, sobre todo en servicios públicos subsidiados, cobrados por debajo de su costo de producción. Esto se reduce a que lo ideal a estos males es la privatización global de los servicios públicos, y forman parte de todos los planes de ajuste, reordenación o modernización de las economías latinoamericanas negociadas con el FMI y la banca multinacional (Padilla, 1991).

Para los opositores a la privatización, lo que entraría en conflicto está ligado con el proceso de producción y la estructura de costo, es decir, serían más caros los servicios y el impacto en la economía familiar produciría "costos políticos".

En el caso de la privatización del servicio de limpia (recolección y confinamiento de residuos sólidos urbanos) existen ya varios casos, sin embargo citamos sólo dos de ellos. De las ciudades mexicanas que presentan algunas similitudes con Ciudad Juárez en cuanto a aspectos demográficos y económicos, se puede enumerar a la ciudad de Chihuahua, en donde, desde el año 2002, el servicio de recolección doméstica se ha concesionado a cinco inversionistas que ofrecen el servicio al 35\% de la ciudad, teniendo una supervisión constante del municipio a través de la Dirección de Limpia, que sigue ofreciendo el servicio al resto de la ciudad y también se encarga del relleno sanitario. ${ }^{5}$

Otro caso es el de Puebla, que desde 1990 concesionó el servicio de recolección a siete inversionistas, tres concesionarios de mercados y 35 pequeños concesionarios de la periferia de la ciudad. Para 1994 el esquema no funcionó, pero lejos de desaparecer este esquema privado, se redujo a sólo dos concesionarios, que dividieron la ciudad en dos sectores (Muñoz, 2004).

${ }^{5}$ Entrevista al ingeniero Jesús Millot, director de Limpia de Chihuahua, Chihuahua, 1 de marzo de 2006. 
Los dos casos se encuentran en un proceso de aprendizaje para mejorar su eficiencia y eficacia y han solventado la crítica de los diferentes actores de estas ciudades demostrando que es posible ser eficientes, adquirir el compromiso social y disminuir el déficit de gasto corriente e inversión en sus respectivos municipios.

\section{Marco metodológico}

Si se plantea la necesidad de evaluar la capacidad ciudadana para influir en las decisiones y acciones públicas, se debe contemplar cuando menos la habilidad del activismo local para lograr que la asignación de los recursos financieros y de los servicios públicos se brinde de acuerdo con la demanda colectiva (Graizboard, 1999).

Para llevar esto a cabo, es preciso evaluar los fenómenos estructurales y aquellos que ocurren al interior del individuo. Para medir los fenómenos estructurales (objetivos) se recurre a la revisión hemerográfica, la entrevista y la encuesta; para medir los fenómenos al interior del individuo (subjetivos) se precisa la entrevista y la encuesta.

Para este trabajo se diseñó un esquema de reconocimiento de las posturas de los diferentes actores relacionados con el servicio de limpia. Entre todos éstos tenemos los que resultaron de la revisión hemerográfica, la encuesta a 200 jefes de hogar y los 11 líderes de opinión que aceptaron una entrevista formal sobre el asunto.

El análisis realizado se alimenta de datos objetivos y subjetivos. Los datos objetivos resultan principalmente de las encuestas y de documentos oficiales o publicaciones académicas, a partir de los que se observan y se tratan de conocer las condiciones de vida materiales de los sujetos en el sistema social y económico.

El análisis cualitativo, o datos subjetivos, resulta al mismo tiempo de la encuesta y del análisis histórico del proceso de gestión del servicio de recolección de basura en la ciudad. Estos datos tienen que pasar por un filtro en donde se interpretan los mensajes discursivos o las acciones de los sujetos, ya sean ciudadanos como actores reconocidos o ciudadanos comunes. 


\section{Los actores en el tiempo}

Para identificar a los actores estratégicos relacionados con el servicio de limpia a través del tiempo se construyó la base de datos hemerográfica sobre el servicio de recolección de basura en Ciudad Juárez de los años de 1976 a 2002, donde se concentran las noticias relacionadas con este tópico y que aparecieron en tres diarios de la ciudad. ${ }^{6}$

El número de notas analizadas y las fuentes de información se aprecian en el cuadro 2.

\section{Los jefes de hogar}

Para analizar la perspectiva de los jefes de hogar fue necesario diseñar dos variables independientes (Mcklosky, 1975): a) las influencias internas al ciudadano, que pueden ser psicológicas y cognoscitivas; y b) las influencias derivadas del ambiente social y político externo al ciudadano.

Cuadro 2.

Frecuencia de notas hemerográficas sobre servicio de recolección de basura en Ciudad Juárez 1976-2002

\begin{tabular}{lcc}
\hline $\begin{array}{l}\text { Fuente de } \\
\text { información o } \\
\text { periódico }\end{array}$ & $\begin{array}{c}\text { Frecuencia de } \\
\text { noticias }\end{array}$ & $\begin{array}{c}\text { Porcentaje } \\
\text { válido }\end{array}$ \\
\hline Diario & 56 & 26.2 \\
Fronterizo & 37 & 17.3 \\
Norte & 121 & 56.5 \\
Total & 214 & 100.0 \\
\hline
\end{tabular}

Fuente: Elaboración propia.

${ }^{6}$ Los diarios considerados para esta revisión fueron El Fronterizo, El Diario de Juárez y El Norte, revisados en la Biblioteca Central de la Universidad Autónoma de Ciudad Juárez. 
En este sentido, se construyeron varios indicadores a nivel micro y macro. Por el lado de la variable micro tenemos a las influencias internas del ciudadano (IIC) cuyos indicadores son la responsabilidad para cuidar el agua y la confianza en las instituciones.

Por el lado de la variable macro destacan las influencias externas del ciudadano (IEC), que abarcan los indicadores del perfil ciudadano y de cobertura y accesibilidad a servicios públicos (cuadro 3).

\section{Cuadro 3.}

Esquema metodológico principal sobre evaluación de actores relacionados con el servicio de limpia en Ciudad Juárez, Chihuahua

\begin{tabular}{|c|c|c|}
\hline Variables (y) & Indicador principal & Indicador secundario \\
\hline \multirow{2}{*}{$\begin{array}{l}\text { I. Influencias internas } \\
\text { del jefe de hogar } \\
\text { (psicológicas y cog- } \\
\text { noscitivas) }\end{array}$} & $\begin{array}{l}\text { 1. Responsabilidad } \\
\text { para mejorar } \\
\text { servicio }\end{array}$ & $\begin{array}{l}\text { a) Conocimiento } \\
\text { b) Disposición }\end{array}$ \\
\hline & $\begin{array}{l}\text { 2. Confianza en } \\
\text { instituciones }\end{array}$ & $\begin{array}{l}\text { a) Confianza en } \\
\text { gobierno }\end{array}$ \\
\hline \multirow{2}{*}{$\begin{array}{l}\text { II. Influencias exter- } \\
\text { nas derivadas del } \\
\text { ambiente social y } \\
\text { político externo al } \\
\text { individuo }\end{array}$} & 3. Ciudadano & $\begin{array}{l}\text { a) Sexo } \\
\text { b) Edad } \\
\text { c) Lugar de } \\
\text { nacimiento } \\
\text { e) Arraigo en colonia } \\
\text { d) Nivel educativo } \\
\text { e) Hacinamiento }\end{array}$ \\
\hline & 4. Servicios & $\begin{array}{l}\text { a) Cobertura de } \\
\text { servicios } \\
\text { b) Recolección de } \\
\text { basura } \\
\text { - Frecuencia } \\
\text { - Puntualidad } \\
\text { - Producción } \\
\text { - Destino }\end{array}$ \\
\hline
\end{tabular}

Fuente: Elaboración propia. 
El análisis de las dos variables parte del estudio de los resultados de un muestreo aleatorio a hogares para aplicar 200 cuestionarios. La muestra fue obtenida con base en una selección de 12 de 406 áreas circulares con un radio de cobertura de 750 metros, es decir, que abarcan 1500 metros de diámetro distribuidas de manera aleatoria en la mancha urbana. ${ }^{7}$ Dichas áreas se establecieron en tres categorías de acuerdo con su nivel de rezago urbano. El nivel bajo cuenta con 311 círculos, el nivel medio con 80 y el nivel alto con 15 círculos.

Además de cada estrato socioeconómico se seleccionaron cuatro círculos al azar para aplicar los 200 cuestionarios distribuidos en partes iguales para cada estrato. El universo resultante fue de 1434 manzanas, de las que se eligieron 200 al azar, lo que representó que del nivel de rezago bajo se seleccionara el $17.67 \%$ de las manzanas totales; del medio el $9.67 \%$ y del alto el $17.96 \%$, como se muestra en el cuadro 4.

La forma de la encuesta fue personal y se entrevistó al responsable del hogar ${ }^{8}$ o a un adulto residente del mismo. Una vez ubicada la manzana, se localizó el lote a partir de ubicarse en la esquina noroeste, y una vez allí, y si había respuesta, se aplicaba el cuestionario; si no la había, se pasaba al lote dos o al que fuera necesario, en el mismo sentido, hasta su aplicación. Una vez levantados los datos se creó una base de éstos con los sistemas Excel y sPss-12 para Windows para su respectivo análisis estadístico.

\footnotetext{
${ }^{7}$ Estas áreas se establecieron para el proyecto "Rescate y Regeneración de Espacios Urbanos Ociosos para la Creación de Parques Ecológicos en un Marco de Desarrollo Sustentable", realizado por Romo y Córdova (2006), de El Colef, con fondos de municipio Juárez y Conacyt. En proceso.

${ }^{8}$ Se define hogar como el conjunto de personas unidas o no por lazos de parentesco que residen habitualmente en la misma vivienda particular y se sostienen de un mismo gasto común principalmente para comer (una persona que vive sola también forma un hogar). El concepto de hogar es entendido como el ámbito social donde los individuos comparten una unidad de vivienda y organizan actividades indispensables para producción sobre la base de un fondo común (concepto de unidad doméstica de una sola dimensión: residencia).
} 
Cuadro 4

Diseño de la muestra para encuesta aleatoria a hogares

\begin{tabular}{|c|c|c|c|c|}
\hline \multirow[b]{2}{*}{ Nivel de rezago social } & \multicolumn{3}{|c|}{ Muestra } & \multirow[t]{2}{*}{ Total } \\
\hline & Bajo & Medio & Alto & \\
\hline Núm. de círculos totales & 311 & 80 & 15 & 406 \\
\hline Núm. de círculos & 4 & 4 & 4 & 12 \\
\hline $\begin{array}{l}\text { Distribución por estrato } \\
\text { socioeconómico }\end{array}$ & 67 & 66 & 67 & 200 \\
\hline Total de manzanas & 379 & 682 & 373 & 1,434 \\
\hline $\begin{array}{l}\% \text { Total de manzanas } \\
\text { seleccionadas }\end{array}$ & 17.67 & 9.67 & 17.96 & 13.94 \\
\hline
\end{tabular}

Fuente: Elaboración propia.

\section{Líderes de opinión}

Los líderes son ciudadanos sensibles al acontecer cotidiano en el manejo de la basura y representan la opinión de sus respectivos sectores; son críticos y tienen poder de influencia en el diseño de las políticas públicas. Se entrevistó a 11 líderes de opinión expertos en el tema del medio ambiente.

\section{Los actores en el tiempo}

Los temas de la gestión

De la revisión hemerográfica se pudo reconstruir el proceso de gestión (toma de decisiones) que los diferentes actores han realizado en la ciudad. En esta reconstrucción de hechos se identificaron 18 temas relacionados con el manejo de la basura; de éstos, se puede observar que los concernientes a la basura especial, costo del servicio, los lotes baldíos, los relacionados con política, la privatización, el servicio de recolección y el sindicato sumaron el $84.1 \%$ de las notas. Entre las temáticas destacan las notas sobre el sindicato y las relacionados con actores políticos en torno al agua (cuadro 5). 
Cuadro 5.

Frecuencia de tópicos o temas de noticias relacionadas con el servicio de recolección de basura

\begin{tabular}{lcr}
\hline $\begin{array}{l}\text { Tópico o tema } \\
\text { de la noticia }\end{array}$ & $\begin{array}{l}\text { Frecuencia } \\
\text { de noticias }\end{array}$ & $\%$ \\
\hline Atención ciudadana & 5 & 2.3 \\
Sindicato & 45 & 21.0 \\
Relacionados con política & 30 & 14.0 \\
Costo de servicio & 25 & 11.7 \\
Lotes baldíos & 25 & 11.7 \\
Recolección & 21 & 9.8 \\
Privatización & 18 & 8.4 \\
Basura especial & 16 & 7.5 \\
Infraestructura y equipo & 8 & 3.7 \\
Contaminación & 5 & 2.3 \\
Llantas & 5 & 2.3 \\
Programas OsC & 3 & 1.4 \\
Reglamento & 2 & 0.9 \\
Relleno sanitario & 2 & 0.9 \\
Relaciones intergubernamentales & 1 & 0.5 \\
DGEPC & 1 & 0.5 \\
SOcose M A & 1 & 0.5 \\
Tiliches & 1 & 0.5 \\
Total & 214 & 100.0 \\
\hline
\end{tabular}

Fuente: Elaboración propia.

En cuanto a los temas relacionados con la basura especial, las notas refieren a los usuarios que producen basura industrial y se les intenta poner orden a partir de un impuesto o derecho de limpia. ${ }^{9}$

El costo de servicio se refiere básicamente al impuesto que el municipio implementó en 1981 por el derecho de limpia a los usuarios, si bien hubo quienes se opusieron a tal medida. ${ }^{10}$

\footnotetext{
9 "Derecho de limpia: usuarios industriales y comerciantes pagarán de 900 a mil pesos, Alcalde Manuel Quevedo", El Norte, 13 de febrero de 1981. Fuente: Córdova, 2005, Base de Datos Hemerográfica Residuos Sólidos en Ciudad Juárez, Chihuahua. 10 "Se inició entrega de los recibos para pago de derechos de limpia. Alcalde Manuel Quevedo", El Norte, 24 de marzo de 1981; “Gracias a Ornelas (gobernador)
} 
Las notas sobre lotes baldíos ${ }^{11}$ relatan la gran cantidad de tiraderos a cielo abierto que proliferan en la ciudad y muestran que a inicios de la década de los noventa existieron denuncias que advertían sobre este problema y la gran cantidad de basura esparcida por las colonias. ${ }^{12}$

Los hechos relacionados con la política son la crónica de la lucha partidista que se da entre el partido que está en el poder (dentro de la presidencia) y los partidos opositores, Por ejemplo, en el caso del impuesto o derecho de limpia el PAN se opone porque según ellos afecta a familias, pero cuando llega al poder es criticado porque no deroga tal impuesto. De esta manera, este tipo de actores buscan la simpatía de los electores para arrebatar el poder municipal. ${ }^{13}$

se dio la implantación del derecho de limpia, Servicios Públicos Municipales", El Norte, 11 de octubre de 1982; "Vecinos de Infonavit se ampararán para no pagar el impuesto de limpia al Ayuntamiento", El Norte, 11 de marzo de 1982; Fuente: Córdova, 2005, Base de Datos Hemerográfica Residuos Sólidos en Ciudad Juárez, Chihuahua.

${ }^{11}$ El modelo de ocupación del suelo en Ciudad Juárez se ha caracterizado por una urbanización acelerada, con bajas densidades y la ocupación de grandes extensiones de terreno. Algunas de las principales causas de dicho modelo son la especulación del suelo, la existencia de una amplia diferencia de ingresos entre los diferentes grupos sociales, la participación de agentes formales e informales dentro de la producción del espacio urbano, los distintos regímenes de propiedad, la errática y cada vez menor participación del estado en las políticas urbanas y sociales, y la poca o nula regulación de las autoridades. Ello se ha traducido en la acelerada expansión de la mancha urbana, en una creciente especulación del suelo, en el aumento de la segregación espacial, y ha originado que la cantidad de predios baldíos aumente (Díaz Arcos, 2004).

12 "Detectan 480 tiraderos clandestinos, proponen la creación de un departamento especial para limpiar éstos", El Norte, 9 de marzo de 1992; "Vecinos se quejaron de basura en la colonia", El Norte, 1 de febrero de 1993. Fuente: Córdova, 2005, Base de Datos Hemerográfica Residuos Sólidos en Ciudad Juárez, Chihuahua.

13 "Impugnarán reglamento de limpia, atenta contra economía de familias, Partido Acción Nacional (PAN)", El Diario, 27 de noviembre de 1982; “El Ayuntamiento sí cobra el derecho de limpia cuando se comprometió a no cobrarlo; el PAN no cumple su promesa, denuncia Efraín Zúñiga, delegado del Partido Revolucionario Institucional (PRI)", El Norte, 8 de octubre de 1984; "El Consejo (PRI) acusa al ex alcalde Gustavo Elizondo (PAN) de que compró camiones (de recolección) muy caros", El Diario, 26 de febrero de 2002. Fuente: Córdova, 2005, Base de Datos Hemerográfica Residuos Sólidos en Ciudad Juárez, Chihuahua. 
En cuanto a la privatización, las noticias aparecen desde 1976, cuando hubo un intento de concesión del servicio por parte de la administración priísta con la oposición del PAN. ${ }^{14}$ No se habló más del asunto hasta que al inicio de su periodo como alcalde, Ramón Galindo sacó a la luz pública el tema enfrentándose al Sindicato de Trabajadores del Municipio y terminando por desistir de tales propósitos. ${ }^{15}$

El servicio de recolección está relacionado con varios factores, entre ellos el sindicato y el servicio que se brinda a los usuarios. En cuanto al primero, se observa que la recolección se ha visto afectada por los frecuentes paros de los trabajadores en demanda de mejoras laborales, y sobre el segundo, a las quejas de algunos vecinos y comerciantes para que se les mejore el servicio. ${ }^{16}$

En cuanto al sindicato, este tema es más frecuente y tiene que ver básicamente con la relación conflictiva permanente entre éste y el municipio, la fuerza que cobra éste en la administración municipal y su integración como corporación en el sistema político local. Los puntos de conflicto permanente están relacionados con los despidos, los paros sindicales y con las amenazas de huelga,17 por su parte, la fuerza del

14 "El PAN ha publicado su inconformidad por su concesión a particulares", El Norte, 22 de agosto de 1976. Fuente: Córdova, 2005, Base de Datos Hemerográfica Residuos Sólidos en Ciudad Juárez, Chihuahua.

15 "Oneroso para Municipio servicio, por eso con plan piloto se puede concesionar, Ramón Galindo, presidente Municipal (1995-1997)", El Norte, 6 de febrero de 1996; "Interesados REDENOR, SEREBA, Transportes Alba, Jorge del Valle, director de SPM", El Norte, 9 de febrero de 1996; "Busca Sindicato intervención del Congreso para evitar privatización", El Norte, 10 de febrero de 1996. Fuente: Córdova, 2005, Base de Datos Hemerográfica Residuos Sólidos en Ciudad Juárez, Chihuahua.

16 "Rehúsan trabajadores de limpia a laborar sin equipo para lluvia, sólo 3 de 24 camiones prestaron servicio", El Norte, 2 de julio de 1992; "150 toneladas de basura se quedan sin recoger el deficiente servicio de limpia, Ignacio Téllez, Municipio", El Norte, 5 de agosto de 1992; "Implementan operativo entre Canaco y dirección de Limpia para erradicar el problema de acumulamiento de basura en la zona centro", El Norte, 10 de julio de 1992; "Piden los de limpia 20 pesos por recoger basura una vez a la semana", El Norte, 10 de abril de 1996. Fuente: Córdova, 2005, Base de Datos Hemerográfica Residuos Sólidos en Ciudad Juárez, Chihuahua.

17 "60 empleados cesados por el municipio en forma arbitraria e injustificada, Sindicato", Fronterizo, 16 de octubre de 1980; "Emplaza sindicato a huelga", El Diario, 26 de septiembre de 1998. Fuente: Córdova, 2005, Base de Datos Hemerográfica Residuos Sólidos en Ciudad Juárez, Chihuahua. 
sindicato se observa en la capacidad de movilización y en la unidad sindical, ${ }^{18}$ de esta manera, la organización se mete de lleno al sistema político participando en elecciones de acuerdo a sus intereses. ${ }^{19}$

\section{Los actores de la gestión}

Del total de los 29 actores identificados de manera particular, se construyen cuatro grupos de actores principales o protagonistas.

El primer actor grupal corresponde al ámbito gubernamental local y se compone por los actores particulares del municipio y de Servicios Públicos Municipales, que juntos suman el $43 \%$ de las notas; el segundo actor grupal es el sindicato, con un $15.9 \%$; el tercer grupo se conforma por los partidos políticos (PAN, PRI, PRD) que suman $10.3 \%$ del total de noticias; y el cuarto y último grupo es la ciudadanía, que se identifica como usuarios del servicio con el $4.7 \%$ de las notas totales (cuadro 6). El 26.1\% restante corresponde a los otros 22 actores.

El municipio se ha dedicado a conseguir y optimizar los recursos para operar el servicio de limpia, buscando esquemas de negociación con el sindicato, los usuarios domésticos, la industria y el comercio. $^{20}$

Después de la escaramuza que se suscitó entre el municipio, el sindicato y algunos actores por el anuncio de la privatización a principios de 1996, la administración del servicio de limpia inició una etapa de

18 "Empleados bloquean camiones recolectores para demandar reinstalación de compañeros", Fronterizo, 13 de septiembre de 1989; "Paran servicios de limpia con 410 sindicalizados", El Diario, 6 de agosto de 1996.

19 "El sindicato hizo boicot al municipio para restarle votos, dijo Pedro César Acosta (PAN)", El Diario, 7 de agosto de 1986. Fuente: Córdova, 2005, Base de Datos Hemerográfica Residuos Sólidos en Ciudad Juárez, Chihuahua.

20 "Se resuelve conflicto y se reinstalan 62 empleados de limpia cesados, Alcalde Manuel Quevedo", Fronterizo, 20 de octubre de 1980; "Disposiciones del Congreso para cobro de recolección de basura, y están por pláticas con sectores, Manuel Quevedo", Fronterizo, 15 de enero de 1981; "Alargan a 6 días jornada laboral: municipio", El Diario, 17 de junio de 1986; "150 toneladas de basura se quedan sin recoger por el deficiente servicio de limpia, Ignacio Téllez, SPM", El Norte, 5 de agosto de 1992. Fuente: Córdova, 2005, Base de Datos Hemerográfica Residuos Sólidos en Ciudad Juárez, Chihuahua. 
Cuadro 6.

Actores principales de las noticias relacionadas con el servicio de recolección de basura en Ciudad Juárez, Chihuahua

\begin{tabular}{llrr}
\hline & Actores principales & $\begin{array}{c}\text { Frecuencia } \\
\text { de noticias }\end{array}$ & \multicolumn{1}{c}{$\%$} \\
\hline 1 & Académicos & 1 & 0.5 \\
2 & AMAC & 1 & 0.5 \\
3 & Boteros / Cartoneros & 4 & 1.9 \\
4 & Canacintra & 2 & 0.9 \\
5 & Canaco & 7 & 3.3 \\
6 & Colonos de periferia & 6 & 2.8 \\
7 & Congreso del Estado & 2 & 0.9 \\
8 & CTM & 2 & 0.9 \\
9 & DGEPC & 4 & 1.9 \\
10 & Empresarios & 2 & 0.9 \\
11 & Gobierno del Estado & 3 & 1.4 \\
12 & Gobierno Federal & 8 & 3.7 \\
13 & Gobierno Internacional & 1 & 0.5 \\
14 & Junta de Conciliación y Arbitraje & 2 & 0.9 \\
15 & Liga Municipal de Organizaciones Populares & 1 & 0.5 \\
16 & Llanteros & 2 & 0.9 \\
17 & Municipio & 51 & 23.8 \\
18 & No indica & 2 & 0.9 \\
19 & Organizaciones de la Sociedad Civil & 2 & 0.9 \\
20 & Otros partidos políticos & 3 & 1.4 \\
21 & Partido Acción Nacional & 14 & 6.5 \\
22 & Partido de la Revolución Democrática & 1 & 0.5 \\
23 & Partido Revolucionario Institucional & 4 & 1.9 \\
24 & Sindicato & 34 & 15.9 \\
25 & Sociedad Cooperativa de Seleccionadores & 1 & \\
& de Materiales & 1 & 0.5 \\
26 & Servicios Públicos Municipales & 42 & 19.6 \\
27 & Unión de Contribuyentes y Usuarios & & \\
& del Servicio Público & 1 & 0.5 \\
28 & Usuarios & 4.7 \\
29 & Yonqueros & 0.5 \\
\hline & Total & & \\
\hline & & 100.0 \\
\hline
\end{tabular}

Fuente: Elaboración propia. 
modernización y mejoramiento del servicio elaborando para ello un marco legal: el Reglamento de Aseo y Regeneración Urbana. ${ }^{21}$

En adelante se observa la preocupación por limpiar los lotes baldíos, comprar equipo e invertir en el servicio de limpia..22 Así, se ha instituido el Programa Destilichadero en las últimas tres administraciones municipales. ${ }^{23}$

Por el lado del sindicato, se aprecia una consolidación, reivindicando las demandas de sus trabajadores ${ }^{24}$ muy frecuentes en un inicio hasta poder abatir el fantasma de la huelga, la amenaza o el chantaje. La última nota sobre paro de labores se observa en El Diario del 14 de septiembre del año 2000.

En cuanto a los partidos políticos, éstos han estado presentes en las discusiones más importantes, como el asunto de la privatización que propuso el presidente municipal panista Ramón Galindo. Cuando en agosto de 1976 el PRI propuso la privatización, el PAN se inconformó y 20 años después apoyó incondicionalmente a su militante. Lo mismo

21 "Con el nuevo reglamento se aplicarán sanciones a vecinos que tengan sucio su frente", El Norte, 18 de abril de 1996. Fuente: Córdova, 2005, Base de Datos Hemerográfica Residuos Sólidos en Ciudad Juárez, Chihuahua.

22 "Existen 35 tiraderos clandestinos y 300 toneladas de basura que no se recogen, SPM", El Diario, 29 de julio de 1999; "Todo establecimiento comercial e industrial que genere 50 kilos por semana deberá pagar o contratar servicio especial, Ing. Jesús Millote, director de Limpia", El Diario, 1 de febrero de 2000; "Adquiere municipio 6 unidades, invierten 200 mil dólares", El Diario, 15 de febrero de 2001; "10 unidades recolectoras, 3 barredoras, 1 volteo, 5 pipas, 1 retro, SPM", El Diario, 30 de junio de 2001; "Inicia operativo destilichadero por el Concejo", El Diario, 24 de febrero de 2002. Fuente: Córdova, 2005, Base de Datos Hemerográfica Residuos Sólidos en Ciudad Juárez, Chihuahua.

${ }^{23}$ El programa de "destilichadero" consiste en ayudar a los ciudadanos a deshacerse de los artículos que ya no quieren en su vivienda y que a la larga pueden representar un peligro al transformarse en nido de alimañas o campo fértil para un incendio. Una de las maneras en que labora es planeando una ruta a seguir en alguna zona determinada de la ciudad, estas visitas se hacen en tres diferentes días de la semana, independientemente del servicio normal de limpia. También puede dar respuesta a las peticiones de Comités de Vecinos o grupo de colonos para llevar los camiones a recolectar todos los tiliches que ellos ya no quieren; éstas también se programan y se les da el servicio los días martes, jueves o el sábado, que son las fechas preestablecidas.

24 "Se nos ha tratado como esclavos y siempre con la amenaza de despido, sindicato", Fronterizo, 17 de octubre de 1980. Fuente: Córdova, 2005, Base de Datos Hemerográfica Residuos Sólidos en Ciudad Juárez, Chihuahua. 
sucede con el PRI: en su momento apoyó la moción, pero después la rechazó. ${ }^{25}$ También los partidos han usado al servicio de limpia como bandera para ganar votos $^{26}$ y como tema para desprestigiar a los adversarios políticos. ${ }^{27}$

Por último, los usuarios han tenido un papel discreto limitándose a exigir un mejor servicio y buscando que la ciudad esté limpia; se observan quejas que han ido disminuyendo con el tiempo y cambiando su demanda de una mejor recolección a fijarse en su medio y denunciar la basura más allá de sus propiedades. ${ }^{28}$

\section{Los jefes de hogar}

\section{Influencias externas del ciudadano}

\section{Ciudadano}

De los jefes de hogar encuestados la mayoría son del sexo femenino, tienen una edad promedio de 39.6 años, con un nivel escolar de 8.18 años de educación formal, su tiempo de residir en la colonia es de casi 16 años, y viven en compañía de 3.56 personas de su familia. Se observa también que la escolaridad disminuye y el hacinamiento aumenta a mayor nivel de rezago.

25 "El PAN ha publicado su inconformidad por su concesión a particulares", El Norte, 22 de agosto de 1976; "Es obligación del municipio prestar el servicio: Regidores PRI-PRD", El Norte, 21 de febrero de 1996. Fuente: Córdova, 2005, Base de Datos Hemerográfica Residuos Sólidos en Ciudad Juárez, Chihuahua. 26 "Luis H. Álvarez, candidato a gobernador, pedirá la derogación del impuesto de limpia", El Diario, 30 de septiembre de 1983.

27 "El servicio de limpia es deficiente, PAN", Fronterizo, 6 de enero de 1988; "Reyes Ferris, presidente de Consejo (PRI), pide que intervenga Congreso del Estado (para ver compra de camiones de su antecesor)" de 2002. Fuente: Base de datos hemerográfica sobre servicio de recolección de basura en Ciudad Juárez 1976-2002; Córdova, 2005, Base de Datos Hemerográfica Residuos Sólidos en Ciudad Juárez, Chihuahua.

28 "El servicio de limpia cada vez es peor, usuarios", Fronterizo, 4 junio de 1981; "Se quejan vecinos de basura en lotes", El Norte, 21 de julio de 2001. Fuente: Córdova, 2005, Base de Datos Hemerográfica Residuos Sólidos en Ciudad Juárez, Chihuahua. 


\section{Cuadro 7.}

Lugar de nacimiento de jefes de hogar encuestados en tres zonas de estudio del servicio de limpia de Ciudad Juárez, Chihuahua

\begin{tabular}{lcccc}
\hline \multirow{2}{*}{ Municipio } & & \multicolumn{3}{c}{ Zonas por nivel de rezago } \\
\cline { 3 - 5 } & General & Bajo & Medio & Alto \\
\hline Juárez & 34.25 & 35.42 & 63.15 & 16.67 \\
Durango & 6.63 & 8.33 & 1.75 & 10.61 \\
Torreón & 5.52 & 10.42 & 5.26 & 3.03 \\
México & 2.76 & 10.42 & 0.00 & 0.00 \\
Delicias & 2.21 & 2.08 & 3.51 & 1.51 \\
Otros & 48.63 & 33.33 & 26.33 & 68.18 \\
Total & 100 & 100 & 100 & 100 \\
\hline
\end{tabular}

Fuente: Elaboración propia, 2006

La mayoría de los jefes de hogar encuestados son del municipio de Juárez, Durango y Torreón, el resto, de otros municipios (cuadro 7); seguidos por los estados de Chihuahua, Durango, Coahuila, Veracruz y Zacatecas, en este orden. Se observa que a mayor nivel de rezago, los jefes de hogar son de otros estados.

\section{Cobertura de servicios}

La cobertura de servicios es alta en lo general, y de manera particular disminuye en el nivel de rezago alto especialmente en los servicios de electricidad, agua entubada y drenaje, teniendo que el servicio de recolección es uno de los dos de más amplia cobertura con $98.9 \%$, al igual que el servicio de alumbrado público, también con el mismo porcentaje; el servicio de electricidad con $97.4 \%$; transporte público con $94.7 \%$, y agua entubada con $91.6 \%$.

La calificación de estos servicios se muestra en el cuadro 8, donde se observa que la recolección de basura presenta buena calificación ( 8.98 con base de 10), disminuyendo ligeramente en el nivel de rezago alto. 


\section{Cuadro 8.}

Calificación promedio de servicio según jefes de hogar encuestados en tres zonas de estudio del servicio de limpia de Ciudad Juárez, Chihuahua

\begin{tabular}{lcccc}
\hline & & \multicolumn{3}{c}{ Zonas por nivel de rezago } \\
\cline { 3 - 5 } Categoría & & Bajo & Medio & Alto \\
& & & & \\
\hline Electricidad & 9.16 & 9.55 & 8.86 & 9.02 \\
Alumbrado público & 7.94 & 8.13 & 7.79 & 7.89 \\
Transporte público & 8.08 & 8.59 & 7.98 & 7.66 \\
Recolección de basura & 8.98 & 9.08 & 9.18 & 8.71 \\
Agua entubada & 9.14 & 9.52 & 8.65 & 9.21 \\
Drenaje & 9.14 & 9.50 & 9.09 & 8.52 \\
\hline
\end{tabular}

Fuente: Elaboración propia, 2006.

\section{Recolección de basura}

En cuanto a la producción de basura por hogar, encontramos que un $39.7 \%$ produce un tambo, ${ }^{29} 23.8 \%$ medio tambo, $14.3 \%$ un cuarto de tambo, $13.8 \%$ más de un tambo, y $8.5 \%$ tres cuartos de tambo a la semana (cuadro 9).

El 53.8\% de la población afirma que produce tiliche de varios tipos como madera $28.5 \%$, juguetes $18.5 \%$, y cartón $2.8 \%$. En lo que respecta al nivel de rezago, los de nivel alto producen madera y los de nivel bajo plástico.

De los productores de tiliche una tercera parte los deja acumulados en casa, otra tercera parte los deposita en el bote de basura, el resto los lleva al relleno sanitario (2.1\%); también se paga al carretonero (3.2\%), o se regala (22\%), y están quienes lo tiran al lote baldío (1.1\%). A mayor nivel de rezago lo acumulan en casa o lo queman, a menor nivel de rezago lo tiran al bote de basura (porque pagan por ello al recolector) o lo regalan (cuadro 10).

${ }^{29}$ Un tambo equivale a 200 litros. 


\section{Cuadro 9.}

Producción de basura por semana según jefes de hogar encuestados en tres zonas de estudio del servicio de limpia de Ciudad Juárez, Chihuahua

\begin{tabular}{lcccr}
\hline & & \multicolumn{2}{c}{ Zonas por nivel de rezago } \\
\cline { 3 - 5 } Categoría & General & Bajo & Medio & Alto \\
\hline 1/4 tambo (200 lts.) & 14.3 & 20.3 & 11.9 & 10.6 \\
$1 / 2$ tambo & 23.8 & 21.9 & 25.4 & 24.2 \\
$3 / 4$ tambo & 8.5 & 3.1 & 13.6 & 9.1 \\
1 tambo & 39.7 & 43.8 & 35.6 & 39.4 \\
Más de 1 tambo & 13.8 & 10.9 & 13.6 & 16.7 \\
Total & 100 & 100 & 100 & 100 \\
\hline
\end{tabular}

Fuente: Elaboración propia, 2006.

Cuadro 10.

Destino del "tiliche" según jefes de hogar encuestados en tres zonas de estudio del servicio de limpia de Ciudad Juárez, Chihuahua

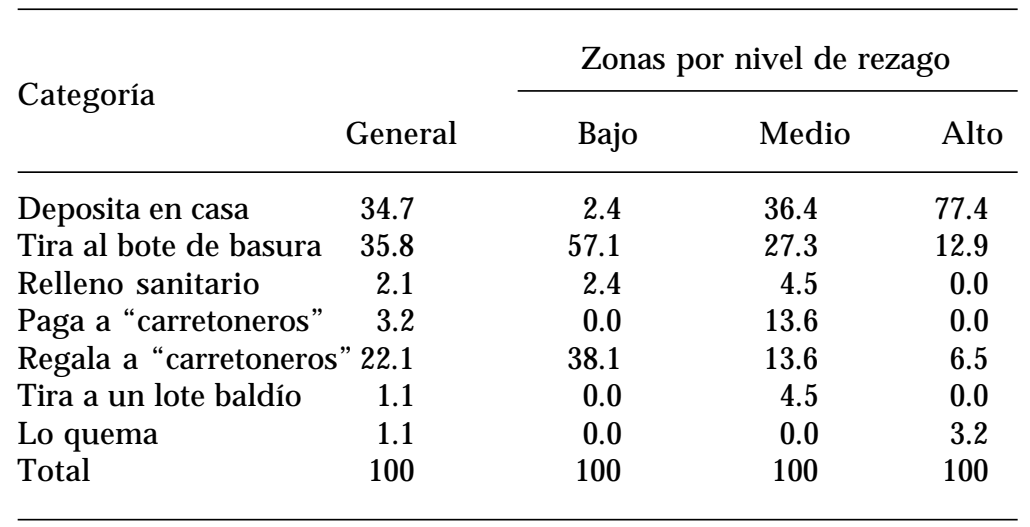

Fuente: Elaboración propia, 2006. 


\section{Influencias internas del ciudadano}

\section{Responsabilidad}

\section{Conocimiento}

La mayoría de los jefes de hogar sabe que Servicios Públicos Municipales le recoge su basura y este saber disminuye ligeramente conforme hay mayor nivel de rezago (cuadro 11). Asimismo, la mayoría están enterados del número de veces que pasa el camión recolector, y se observa en este caso que hay colonias en donde el camión pasa sólo una vez; esto lo manifestó el $21.5 \%$ de los jefes de hogar del nivel de rezago alto.

En cuanto a la puntualidad del servicio de recolección, la mayoría considera que es regular en cuanto al día. Por zona, a menor rezago mayor impuntualidad. Asimismo, la mayoría de los jefes de hogar considera que el servicio es puntual en cuanto a la hora de recolección.

En lo que respecta al conocimiento de destino de su basura, la mayoría desconoce el lugar de depósito final de los desechos y se mantiene

\section{Cuadro 11.}

Conocimiento sobre el recolector de basura de jefes de hogar encuestados en tres zonas de estudio del servicio de limpia de Ciudad Juárez, Chihuahua

\begin{tabular}{lcccc}
\hline \multirow{2}{*}{ Categoría } & & \multicolumn{2}{c}{ Zonas por nivel de rezago } \\
\cline { 3 - 5 } & General & Bajo & Medio & Alto \\
\hline $\begin{array}{l}\text { Empresa privada } \\
\text { Gobierno }\end{array}$ & 0.00 & 0.0 & 0.00 & 0.00 \\
Servicios públicos & 2.66 & 0.0 & 1.72 & 6.06 \\
Municipales & 85.11 & 100.0 & 77.59 & 77.27 \\
No sabe & 12.23 & 0.0 & 20.69 & 16.67 \\
Total & 100 & 100 & 100 & 100 \\
\hline
\end{tabular}

Fuente: Elaboración propia, 2006. 
constante con excepción del nivel de rezago alto, donde el desconocimiento es mayor (cuadro 12).

En cuanto a la limpieza o suciedad de la ciudad, la mayoría de los jefes de hogar manifestaron que la ciudad está sucia $(68.5 \%)$ y muy sucia (18\%) (cuadro 13). Se observa que los de nivel de rezago medio y alto califican a la ciudad como muy sucia.

\section{Cuadro 12.}

Conocimiento sobre el destino de la basura de jefes de hogar encuestados en tres zonas de estudio del servicio de limpia de Ciudad Juárez, Chihuahua

\begin{tabular}{lcccc}
\hline \multirow{2}{*}{ Categoría } & & \multicolumn{3}{c}{ Zonas por nivel de rezago } \\
\cline { 3 - 5 } & General & Bajo & Medio & Alto \\
\hline Sí & 32.4 & 38.1 & 42.4 & 18.2 \\
No & 67.6 & 61.9 & 57.6 & 81.8 \\
Total & 100 & 100 & 100 & 100 \\
\hline
\end{tabular}

Fuente: Elaboración propia, 2006.

Cuadro 13.

Opinión sobre la ciudad según jefes de hogar encuestados en tres zonas de estudio del servicio de limpia de Ciudad Juárez,

Chihuahua

\begin{tabular}{lcccr}
\hline \multirow{2}{*}{ Categoría } & & \multicolumn{3}{c}{ Zonas por nivel de rezago } \\
\cline { 3 - 5 } & General & Bajo & Medio & Alto \\
\hline Limpia & 12.4 & 24.1 & 3.6 & 9.4 \\
Sucia & 68.5 & 53.4 & 82.1 & 70.3 \\
Muy sucia & 18.0 & 20.7 & 14.3 & 18.8 \\
Regular & 1.1 & 1.7 & 0.0 & 1.6 \\
Total & 100 & 100 & 100 & 100 \\
\hline
\end{tabular}

Fuente: Elaboración propia, 2006. 
En lo relacionado a la recolección para la disposición final, un $54.2 \%$ de los jefes de hogar encuestados manifestó que el servicio es incompleto, es decir, los camiones no se llevan todo lo que se genera en el hogar. Por nivel de rezago se observa que a menor rezago mayor exigencia porque los camiones se lleven todo. Esto puede explicarse por la cantidad de basura de tipo especial producida, como madera, cartón, plásticos, etcétera.

La opinión sobre la frecuencia de recolección de basura por semana es generalizada en el sentido de que ésta sea dos veces por semana, con una ligera tendencia a que en niveles de rezago bajo pase el camión tres veces (cuadro 14). Asimismo, es general la opinión de conservar el sistema de tambo tradicional fuera de casa, sin embargo se puede apreciar que los jefes de hogar del nivel de rezago alto consideran en una buena proporción (42.2\%) que se considere el contenedor colectivo cerca de casa.

\section{Disposición}

En lo referente a la disposición para construir un área para depósito de basura, dos terceras partes de los jefes de hogar encuestados no

\section{Cuadro 14}

Opinión sobre la frecuencia de recolección de basura por semana según jefes de hogar encuestados en tres zonas de estudio del servicio de limpia de Ciudad Juárez, Chihuahua

\begin{tabular}{lcrrr}
\hline & & \multicolumn{2}{c}{ Zonas por nivel de rezago } \\
\cline { 3 - 5 } Categoría & & Bajo & Medio & Alto \\
\hline Una vez & 4.8 & 1.6 & 3.4 & 9.1 \\
Dos veces & 86.2 & 82.8 & 87.9 & 87.9 \\
Tres veces & 9.0 & 15.6 & 8.6 & 3.0 \\
Más de tres veces & 0.0 & 0.0 & 0.0 & 0.0 \\
Total & 100 & 100 & 100 & 100 \\
\hline
\end{tabular}

Fuente: Elaboración propia, 2006. 


\section{Cuadro 15.}

Razón por la que no se tiene disposición para construir un área para depósito de basura según jefes de hogar encuestados en tres zonas de estudio del servicio de limpia de Ciudad Juárez, Chihuahua

\begin{tabular}{lcrrr}
\hline & & \multicolumn{2}{c}{ Zonas por nivel de rezago } \\
\cline { 3 - 5 } Categoría & General & Bajo & Medio & Alto \\
\hline No tiene dinero & 23.4 & 4.8 & 18.2 & 37.5 \\
No lo cree necesario & 53.2 & 81.0 & 54.5 & 37.5 \\
No es su obligación & 18.1 & 9.5 & 21.2 & 20.0 \\
Otras causas & 5.3 & 4.8 & 6.1 & 5.0 \\
Total & 100 & 100 & 100 & 100 \\
\hline
\end{tabular}

Fuente: Elaboración propia, 2006.

están dispuestos a construir un área de almacenamiento temporal de la basura de su hogar, por considerarla innecesaria, principalmente en el nivel de rezago bajo, y por falta de dinero a mayor nivel de rezago (cuadro 15).

En relación al conocimiento y disposición de pago, el 95\% desconoce sobre el derecho de cobro, con una ligera tendencia a que a menor rezago mayor conocimiento, que es donde precisamente se encuentra la gente nacida en la ciudad y que tal vez se acuerdan de este cobro en las décadas pasadas.

En cuanto a la disposición del pago mensual por el servicio de recolección de basura, la opinión está dividida en lo general. Por nivel de rezago, encontramos que la mayoría del nivel de rezago bajo sí está dispuesta a efectuar algún pago, mientras que en los niveles medio y alto la tendencia es contraria.

De los que sí están dispuestos a pagar, la mayoría (68\%) accede a pagar menos de 50 pesos. Por nivel de rezago, localizamos que en el nivel medio existe cerca de un $42 \%$ de jefes de hogar dispuestos a pagar entre 50 y 100 pesos al mes (cuadro 16). 


\section{Cuadro 16.}

Cantidad que se está dispuesto a pagar por el servicio según jefes de hogar encuestados en tres zonas de estudio del servicio de limpia de Ciudad Juárez, Chihuahua

\begin{tabular}{|c|c|c|c|c|}
\hline \multirow{2}{*}{ Categoría } & \multirow[b]{2}{*}{ General } & \multicolumn{3}{|c|}{ Zonas por nivel de rezago } \\
\hline & & Bajo & Medio & Alto \\
\hline Menos de $\$ 50$ & 68.1 & 72.5 & 58.3 & 70.0 \\
\hline Entre $\$ 50$ y $\$ 100$ & 30.9 & 27.5 & 41.7 & 26.7 \\
\hline Más de $\$ 100$ & 1.1 & 0.0 & 0.0 & 3.3 \\
\hline Total & 100 & 100 & 100 & 100 \\
\hline
\end{tabular}

Fuente: Elaboración propia, 2006.

Confianza en el gobierno

En general se pudo constatar que existe una alta confianza en el gobierno, especialmente el municipal. Los jefes de hogar consideran que debe ser el gobierno municipal quien administre el servicio de limpia (cuadro 17). Asimismo, la mayoría no identifica a otro organismo aparte del municipio que se encargue de la basura en su comunidad. También se pudo constatar que quien puede dar un mejor servicio según los jefes de hogar es el gobierno de la ciudad, seguido de una empresa mexicana y en menor proporción una empresa americana. Por nivel de rezago, esta tendencia se mantiene constante.

\section{Los líderes de opinión}

La opinión de algunos líderes conocedores de la problemática ambiental de Juárez indica que la administración municipal debería hacer un cambio en su estructura administrativa para dar entrada al esquema de privatización (participación del capital privado) en el servicio de limpia.

La opinión condensada se presenta en el cuadro 18, donde queda de manifiesto la intención que ha tenido el municipio, como lo de- 
Cuadro 17.

Opinión sobre quién debe administrar el sistema de limpia según jefes de hogar encuestados en tres zonas de estudio del servicio de limpia de Ciudad Juárez, Chihuahua

\begin{tabular}{lcccc}
\hline & & \multicolumn{3}{c}{ Zonas por nivel de rezago } \\
\cline { 3 - 5 } Categoría & & Bajo & Medio & Alto \\
\hline Gobierno federal & 1.05 & 1.56 & 0.0 & 1.52 \\
Gobierno estatal & 2.65 & 0.0 & 1.7 & 6.06 \\
Gobierno municipal & 71.96 & 81.25 & 71.2 & 63.64 \\
Empresa privada & 5.29 & 9.38 & 1.7 & 4.54 \\
Organismo ciudadano & 0.00 & 0.00 & 0.0 & 0.00 \\
Otro & 0.53 & 1.56 & 0.0 & 0.00 \\
No sabe & 18.52 & 6.25 & 25.4 & 24.24 \\
Total & 100 & 100 & 100 & 100 \\
\hline
\end{tabular}

Fuente: Elaboración propia, 2006.

muestra el Plan de Desarrollo Urbano de esta administración; sin embargo, en el caso de limpia, el Plan Municipal de Desarrollo no es claro en este propósito ya que sólo menciona el Programa Destilichadero, el programa especial de la "ruta del asco" y la optimización de las rutas de servicio (PMD, 2005).

\section{Conclusiones}

Los servicios públicos de consumo colectivo, como el de los residuos sólidos no peligrosos urbanos, representan una alta responsabilidad estipulada en la Constitución para los municipios. En Ciudad Juárez, la prestación del servicio de limpia significa una importante erogación de recursos públicos. En este sentido, en ciudades de gran desarrollo económico como ésta, existe una alta polarización en los niveles de ingreso y educación que obligan a las administraciones a subsidiar el costo de dicho servicio.

La tendencia mundial es la privatización de los servicios de consumo colectivo, de acuerdo con directrices de la banca de desarrollo 


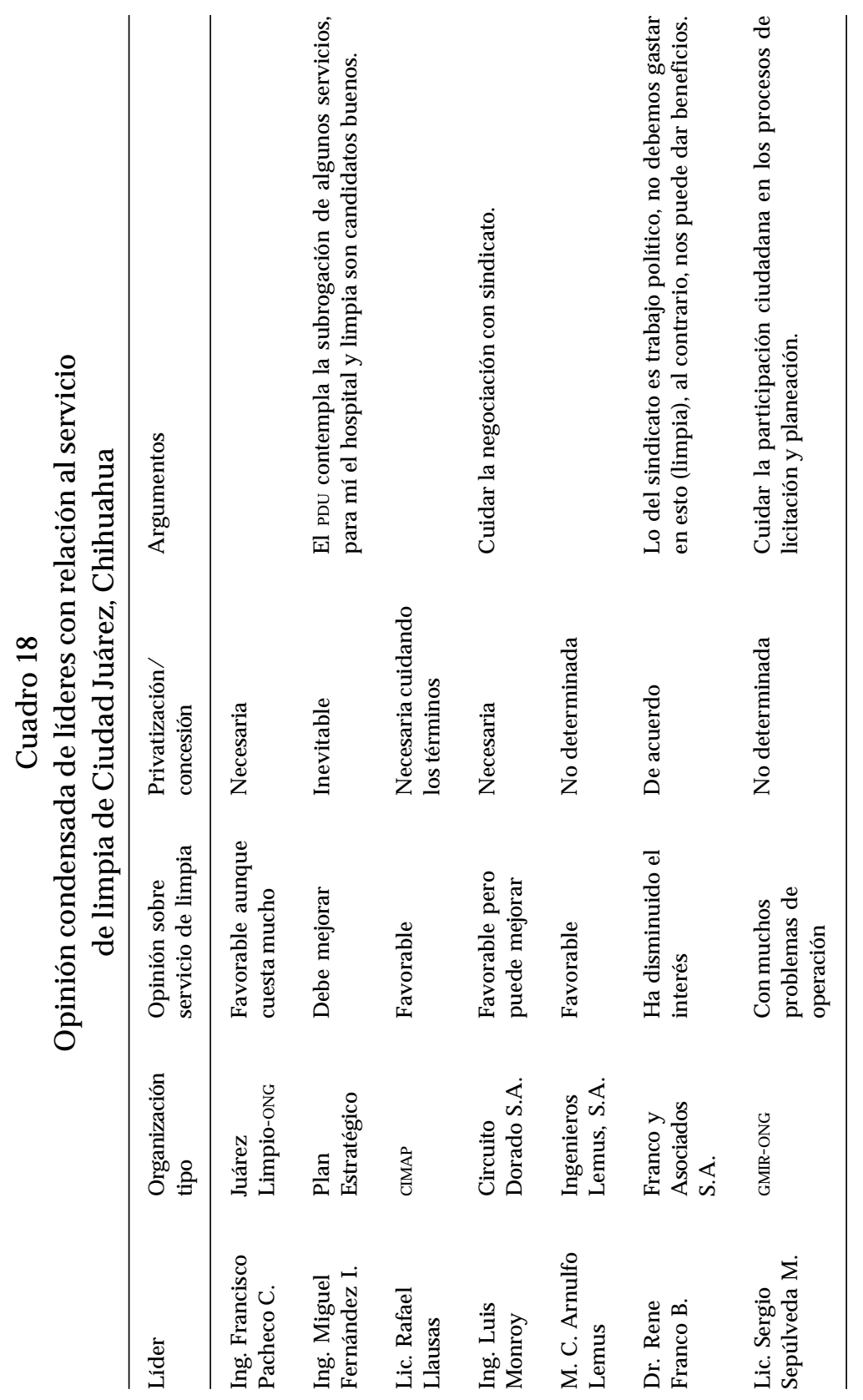




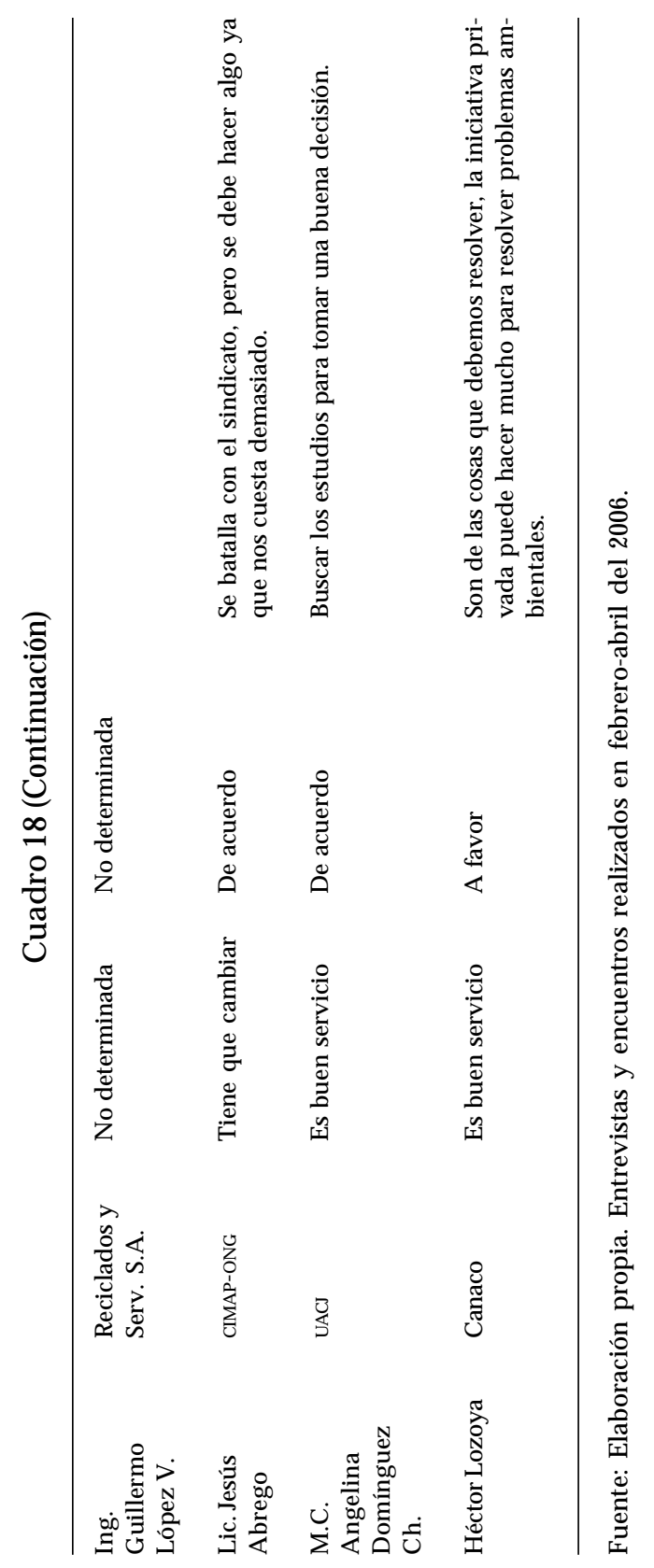


y de la promoción del modelo neoliberal por el fomento del libre mercado y la competencia en todos los niveles económicos.

El sistema económico mexicano, así como la economía local, están influenciados todavía por el sistema político, cuando la tendencia mundial es diferenciar los sistemas sociales. En el caso que nos ocupa, el Estado sigue firme en algunas tareas que históricamente le han correspondido. Gracias al crecimiento del sector servicios por parte de la iniciativa privada, es posible encontrar propuestas técnicas y financieras viables que tengan sentido social; sin embargo, en caso de que el gobierno municipal ceda esta responsabilidad, debe hacerlo con ventajas sustanciales a la comunidad.

En efecto, podemos apreciar la alta politización en el manejo de la basura en la ciudad. Debemos considerar para este caso, que más de una tercera parte de las notas de la revisión hemerográfica realizada son de tipo político y sindical, esto último imposible de disociar de la política partidista y de relaciones de poder local. En este sentido, podemos afirmar que la tendencia mundial va encaminada a mejorar los servicios, no están por la privatización, ni por la existencia de sindicatos ni por la estatización, sino porque los servicios públicos sean eficientes, transparentes, eficaces, y permitan a la población apropiarse de esos bienes de consumo colectivo por medio de la participación activa en la toma de decisiones.

Se observa también que el Ayuntamiento de Juárez se enfrenta cada vez más con la complejidad en el manejo del servicio de limpia. El cambio vertiginoso de las leyes en la materia, el crecimiento de su aparato burocrático y lo que significa pagar pensiones y jubilaciones, y la presión de varios actores que buscan participar de las decisiones de gobierno, hacen que éste tenga que invertir cada vez más recursos materiales y humanos.

$\mathrm{Al}$ respecto, vemos que en los últimos años han surgido varios actores interesados en la recolección y reciclado de la basura. Algunos productores de desechos, como los "llanteros" y los "yonqueros", han exigido participar en la toma de decisiones y se han involucrado en varios proyectos tendientes a resolver la problemática que ellos generan. Por tanto, la administración municipal ha tenido que negociar con ellos a través de acuerdos de trabajo teniendo como mediador 
una organización de gestión mixta de cuatro actores: ${ }^{30}$ el Grupo de Manejo Integral de Residuos de Juárez, creado en febrero de 2003.

Asimismo, las negociaciones y los enfrentamientos se realizan con varios prestadores de servicio de recolección de basura de manejo especial, con varias asociaciones civiles y con las cámaras empresariales. Todo esto obliga a la autoridad a tener una gestión democrática y a elaborar una mejor normatividad y aplicar programas de vigilancia.

Se observa en este sentido una falta de normalización de las relaciones sociales, lo que se traduce en que tengamos una ciudad sucia, como lo manifiestan la mayoría de los jefes de hogar. El esfuerzo gubernamental en los últimos lustros se centra en administrar la recolección y la disposición final, dejando programas y proyectos de limpieza ("destilichadero", llantas, educación ambiental) con presupuesto y recursos humanos insuficientes para cambiar la imagen de la ciudad.

En el caso de los jefes de hogar, es claro que no quieren que se les mueva el statu quo del servicio al considerarlo eficiente y eficaz, sin embargo se muestran desconocedores del tema y no manifiestan disposición para comprometerse con mejorar el servicio, y apuestan a que la autoridad municipal lo resolverá de alguna manera. Mientras se les asegure la misma eficiencia no les importaría quién les ofrezca el servicio ni qué hagan con su basura puesto que confían en el gobierno de la ciudad.

En las entrevistas con algunos de los líderes más importantes sobre el tema, queda manifiesta la tendencia a la privatización por considerar que el servicio es caro y la ciudad se encuentra sucia, y que es necesario un trabajo político hacia dentro de la administración, especialmente con el sindicato, y un trabajo político hacia fuera con los ciudadanos y con los sectores empresariales.

Hacia dentro, independientemente de la privatización de algunos de los servicios de limpia, es importante una reforma administrativa

${ }^{30}$ Se han identificado varios grupos de gestión mixta de cuatro actores en la ciudad en donde participan: $a$ ) el gobierno, $b$ ) las ONG y ciudadanía en general, c) los empresarios y d) los académicos. Los grupos más activos son: Grupo Fuerza de Tarea del Agua Paso del Norte, Plan Estratégico de Juárez, A.C., Ciudadanos por una Mejor Administración Pública A.C. y el Grupo de Manejo Integral de Residuos de Juárez. 
que promueva el redimensionamiento de la función pública en cuanto al servicio de limpia, que tiene que ver con el marco normativo, institucional y operativo; considerando que la ciudad es el tiradero de mercancías de desecho de nuestro "vecino del norte", la basura no es valorada por la población, pues la ciudad sufre una expansión territorial desmedida, existe una baja cultura del manejo de la basura en la sociedad y hay que recoger la que por años ha quedado esparcida en la mancha urbana.

En los últimos meses, la presente administración municipal ha iniciado el proceso de concesión del servicio de recolección y confinamiento de la basura en el relleno sanitario, el cual contempla, entre otras cosas, la concesión por 15 años de este servicio pagando anualmente una cuota de 130 millones de pesos (mdp) al concesionario. Las ventajas que argumenta es el ahorro de $13 \mathrm{mdp}$ por la diferencia con la erogación actual, que es de 143 mdp, el ahorro en la liquidación de 643 plazas y la compra de parque vehicular, que lo haría en todo caso el concesionario. Junto con esto, se ofrece la oportunidad de adelgazar el aparato burocrático y con ello el pago de jubilaciones y servicios médicos, un cambio de política acorde con las tendencias en administración gerencial de la administración pública.

Si las cosas se dan de esta manera, evidentemente hay ventajas en el corto y mediano plazo, sin embargo, habría que seguir de cerca este cambio repentino en la política municipal, si consideramos que este servicio ha estado ofreciéndose desde siempre con buenos resultados y se ha creado infraestructura y recursos técnicos y humanos de primer orden.

Desde el punto de vista financiero, la razón principal es la inversión de corto plazo que hay que hacer para comprar camiones recolectores; desde el punto de vista político, no pasa nada, toda vez que el sindicato sigue en pie; pero desde otra trinchera, la administración municipal y política interior de la administración cambia: de ser eminentemente operativa pasaría a ser normativa; desde el punto de vista social, hay indiferencia en la población en general y júbilo en la mayoría de los actores que participan activamente en la generación de la ciudad. 


\section{Bibliografía}

Díaz Archos, Israel (2004), "El caso de los lotes baldíos en Ciudad Juárez, Chihuahua, 2004: una propuesta de planeación urbana", tesis de maestría, UAC, Ciudad Juárez, Chihuahua.

Garza, G. (1985), El proceso de industrialización en la ciudad de México, 1821-1970, El Colegio de México, México.

Graizboard, B. (1999), “Planeación urbana, participación ciudadana y cambio social", Economía, Sociedad y Territorio, vol. II, núm. 5. El Colegio de México, pp. 149-161.

Mcklosky, H. (1975), Enciclopedia Internacional de las Ciencias Sociales, tomo 7, Aguilar, Madrid.

Meny, Y. y J.C. Thoenig (1992), Las políticas públicas, Ariel, Barcelona. Muñoz, G. (2004), "Política de limpia en Puebla: toma de decisiones y aprendizaje", Ciudades, núm. 64, RNIU, pp. 35-41.

Ordoñez, G. y T. Alegría (1991), “Los servicios públicos en la encrucijada", Ciudades, núm. 11, RNIU, pp. 2-8.

Pirez, P. (1999), "Servicios urbanos: sociedad local y distribución económica en un contexto de reformas y privatizaciones", en E. Patiño y J. Castillo, Servicios y marco construido, RNIU-UAM-A y UACJ.

Plan Municipal de Desarrollo (2004-2007). Ayuntamiento de Juárez. 3 de febrero de 2005.

Padilla, E. (1991), "Privatización de los servicios públicos", Ciudades, núm. 9, RNIU, pp. 2-8.

Restrepo, D. (2001), "Eslabones y precipicios entre participación y democracia", Revista Mexicana de Sociología, vol. LXIII, núm. 3, sept., pp. 167-191.

Romo L. y G. Córdova (2006), "Proyecto: Rescate y Regeneración de Áreas Verdes para Parques Ecológicos en el Marco del Desarrollo Sustentable", El Colegio de la Frontera Norte, con fondos de Municipio Juárez y Conacyt. En proceso.

Saade, L. (2005), Participación de la iniciativa privada en la provisión de los servicios de agua potable y saneamiento en México, documento de trabajo núm. 2, El Colegio de México, Fundación G. Arronte y UNAM. 
Villers, R. (2004), "Servicios públicos y nuevas formas de gestión", Ciudades, núm. 61, RNIU, pp. 57-59.

\section{Entrevistas}

Ing. Ricardo Abud, director técnico de la Dirección General de Servicios Públicos (16 de mayo de 2006).

Ing. Jesús Millot, director de Limpia de Chihuahua, Chih. (1 de marzo de 2006).

Ing. Francisco Pacheco, Organización Juárez Limpio (febrero de 2006).

Ing. Miguel Fernández, Plan Estratégico de Ciudad Juárez (febrero de 2006).

Lic. Rafael Llausas, Ciudadanos para una Mejor Administración Pública (febrero de 2006).

Ing. Luis Monroy, Circuito Dorado S.A. (febrero de 2006).

M.C. Arnulfo Lemus, Ingenieros Lemus S.A. (febrero de 2006).

Dr. René Franco, Franco y Asociados, S.A. (febrero 2006).

Lic. Sergio Sepúlveda M., Grupo de Manejo Integral de Residuos de Juárez (febrero de 2006).

Ing. Guillermo López V., Reciclados y Servicios, S.A. (febrero de 2006).

Lic. Jesús Abrego, Ciudadanos para una Mejor Administración Pública (febrero de 2006).

M. A. Angelina Domínguez Ch., Universidad Autónoma de Ciudad Juárez (febrero de 2006).

Héctor Lozoya, Cámara Nacional de Comercio (febrero de 2006). 